\title{
Stigmatization in Arabic psoriatic patients in the United Arab Emirates - a cross sectional study
}

\author{
Dimitre Dimitrov ${ }^{1}$, Łukasz Matusiak², Jacek C. Szepietowski² \\ ${ }^{1}$ Presidential Medical Wing, Al Mafraq and Sheikh Khalifa Medical City, Abu Dhabi, United Arab Emirates \\ ${ }^{2}$ Department of Dermatology, Venereology and Allergology, Wroclaw Medical University, Wroclaw, Poland \\ Adv Dermatol Allergol 2019; XXXVI (4): 425-430 \\ DOI: https://doi.org/10.5114/ada.2018.80271
}

\begin{abstract}
Introduction: Stigmatization is the phenomenon of labeling negatively people who differ from social norms in some aspect. It seems to be a common and important problem in dermatology. Psoriasis, being a chronic and recurrent skin disease, is frequently associated with various psychosocial consequences.

Aim: To evaluate the stigmatization level in an Arabic population of psoriatic individuals.

Material and methods: A total of 108 consecutive patients suffering from psoriasis were enrolled in the study. All recruited subjects were of Arabic origin. Severity of psoriasis was documented with the Psoriasis Area and Severity Index (PASI). Stigmatization was assessed with validated Arabic language versions of the 6-item Stigmatization Scale and the Feelings of Stigmatization Questionnaire. Moreover, all patients were asked to complete the Dermatology Life Quality Index (DLQI) questionnaire.

Results: The majority of patients showed feelings of stigmatization due to psoriasis. The mean level of stigmatization was $5.6 \pm 4.5$ points assessed by the 6 -item Stigmatization Scale and $98.4 \pm 26.4$ points by the Feelings of Stigmatization Questionnaire. Positive attitudes and feeling of being flawed were the most bothersome aspects of stigmatization expressed by patients. Involvement of the face appeared to be the only independent factor influencing the stigmatization level. In the Feelings of Stigmatization Questionnaire, itching was found to be a factor responsible for feelings of stigmatization.

Conclusions: Our study indicated that stigmatization is common among psoriatic Arabic patients. We postulate that measurement of stigmatization level could contribute to the holistic therapeutic approach of psoriatic patients.
\end{abstract}

Key words: quality of life, stigmatization, psoriasis.

\section{Introduction}

Stigmatization is the phenomenon of labeling negatively people who differ from social norms in some aspect. A number of medical conditions are recognized at present as stigmatizing their sufferers, and certain skin diseases are among them. Going back in history, the world "stigma" originated in ancient Greek language. Its meaning and connotation has varied considerably over the centuries. At present, stigma is defined as a discrediting mark, biological or social, that sets a person off from others and disrupts interactions with them [1]. Various forms stigma can take, for instance: stereotyping, distrust, fear, or avoidance. Stigmatization begins when individuals with a discrediting mark are labeled by another individual or a group. Those individuals become label carriers of the marks they carry [2]. Stigma does not necessarily need to be a visible flaw or mark. It can also be a specific feature, situation or past experience, which is usually associated with negative stereotypes, leading to social discrimination [3]. More detailed definitions explain that stigmatization may also lead to social discrimination and alienation. In such circumstances stigma can overlap with discrimination, reaching the point where the stigmatized ones are denied personal and civil rights [4]. Distinguishing characteristics may result in social disapproval, and visible lesions may become a reason for stigmatization, with consequent psychological stress and social withdrawal [5].

Stigmatization has been studied in some dermatological conditions and seems to be a common and important problem in dermatology. Our review of English literature up to November 2016 found that stigmatization has been studied in twenty different dermatological conditions [6]. Psoriasis was found to be the most frequently studied skin disease.

Psoriasis is a common, chronic, disfiguring, inflammatory and proliferative condition of the skin, in which

Address for correspondence: Prof. Dr. Jacek C. Szepietowski, Department of Dermatology, Venereology and Allergology, Wroclaw Medical University, 1 Chalubińskiego St, 50-368 Wroclaw, Poland, e-mail: jacek.szepietowski@umed.wroc.pl Received: 9.10.2018, accepted: 5.11.2018. 
both genetic and environmental influences have a critical role [7]. Numerous psychological disorders have been described among patients with psoriasis: low mood, depression, and suicidal ideation all are higher among

Table 1. Demographic characteristics and clinical data of psoriatic patients

\begin{tabular}{|c|c|c|}
\hline Variables & $N$ & $\%$ \\
\hline \multicolumn{3}{|l|}{ Gender: } \\
\hline Male & 65 & 60.2 \\
\hline Female & 43 & 39.8 \\
\hline \multicolumn{3}{|l|}{ Marital status: } \\
\hline Single & 29 & 26.9 \\
\hline Married & 79 & 73.1 \\
\hline \multicolumn{3}{|l|}{ Education: } \\
\hline Primary school & 2 & 1.9 \\
\hline Secondary school & 8 & 7.4 \\
\hline High school & 41 & 37.9 \\
\hline University & 57 & 52.8 \\
\hline \multicolumn{3}{|l|}{ Employment: } \\
\hline Employed & 75 & 69.4 \\
\hline Unemployed & 33 & 30.6 \\
\hline \multicolumn{3}{|l|}{ Place of living: } \\
\hline Countryside & 12 & 11.1 \\
\hline Town (< 100,000 citizens) & 31 & 28.7 \\
\hline City ( $\geq 100,000$ citizens) & 65 & 60.2 \\
\hline \multicolumn{3}{|l|}{ Family history of psoriasis: } \\
\hline Yes & 49 & 45.4 \\
\hline No & 59 & 54.6 \\
\hline \multicolumn{3}{|l|}{ PASI: } \\
\hline 0-10.0 & 92 & 85.1 \\
\hline $10.1-20.0$ & 12 & 11.1 \\
\hline $20.1-30.0$ & 2 & 1.9 \\
\hline$>30.0$ & 2 & 1.9 \\
\hline \multicolumn{3}{|c|}{ Duration of disease exacerbation [months]: } \\
\hline$<3$ & 22 & 20.4 \\
\hline$\geq 3$ & 86 & 79.6 \\
\hline \multicolumn{3}{|l|}{ Itching: } \\
\hline Present & 85 & 78.7 \\
\hline Absent & 23 & 21.3 \\
\hline \multicolumn{3}{|l|}{ Joint involvement: } \\
\hline Present & 34 & 31.5 \\
\hline Absent & 74 & 68.5 \\
\hline \multicolumn{3}{|l|}{ Lesions on the face: } \\
\hline Present & 37 & 34.3 \\
\hline Absent & 71 & 65.7 \\
\hline
\end{tabular}

psoriatic patients in comparison to other dermatological disorders or even long-standing non-dermatological conditions [8]. Stigmatization has been found to be a central experience of patients with psoriasis with a broad psychological and social impact[9].

\section{Aim}

Most of the research on stigmatization experience among psoriasis patients has been performed in the western world. There is a lack of studies on stigmatization in Arabic patients suffering from skin diseases. Therefore, the current study was undertaken to evaluate the stigmatization level in an Arabic population of psoriatic individuals.

\section{Material and methods \\ Material}

The study was conducted in the Dermatology Department of Sheikh Khalifa Medical City (SKMC), General Hospital in Abu Dhabi, United Arab Emirates (UAE) and in the Department of Dermatology, Venereology and Allergology of Wroclaw Medical University in Wroclaw, Poland. All recruited subjects were patients of Sheikh Khalifa Medical City (SKMC), General Hospital in Abu Dhabi, UAE and they were all of Arabic origin. Approvals from the Institutional Review Board/Research Ethics Committee (IRB/REC) of SKMC as well as from the Ethical Committee of Wroclaw Medical University in Wroclaw, Poland were obtained prior to commencement of any study procedure.

One hundred seventeen consecutive adult outpatients with a confirmed diagnosis of psoriasis were invited to participate in the study. Nine of them refused participations due to lack of time or limited interest. Finally, 108 psoriatic individuals were recruited into the current study (response rate: $92.3 \%$ ). The studied group consisted of 43 females and 65 males. They mean age was $36.6 \pm 11.2$ years (range: $18-71$ years). The mean age of psoriasis onset was $22.7 \pm 12.5$ years (range: $1-65$ years). Demographic characteristics and clinical data of studied patients are given in Table 1. All patients were on systemic or topical antipsoriatic treatment, with 54 (50\%) subjects receiving biological therapy.

\section{Methods}

All patients signed informed consent prior to any procedure in the study. The demographic data were collected using a structured questionnaire from all the patients during their visit to the dermatology clinic. The severity of psoriasis was assessed with Psoriasis Area and Severity Index (PASI) [10]. Moreover, the intensity of itching (worst itching) during the last 3 days was evaluated by the Visual Analog Scale (VAS) [11]. All patients were asked 
to complete Arabic versions (previously developed by our group) of stigmatization questionnaires: the 6-item Stigmatization Scale and the Feelings of Stigmatization Questionnaire [12].

In the 6-item Stigmatization Scale [13] patients had to answer 6 questions using one of four possibilities scored from 0 to 3 points: "not at all", "sometimes", "very often", and "always". Higher scoring meant a greater feeling of stigmatization (range: $0-18$ ). In the Feelings of Stigmatization Questionnaire [14] patients had to give answers to 33 items using one of 6 possibilities scored from 0 to 5 : "definitely yes”, “yes”, "probably yes”, "probably no”, "no”, "definitely no". The overall scoring could range from 0 to 165 points. In contrast to the 6-item Stigmatization Scale, the lower the score is, the more severe are the patient's feelings of stigmatization. The questions were designed to explore 6 different dimensions of the stigma: anticipation of rejection (8 items), feeling of being flawed ( 6 items), sensitivity to the opinions of others (5 items), guilt and shame ( 5 items), secretiveness ( 5 items), and positive attitudes (4 items) (for details: see [14]). Additionally to stigmatization instruments the patients completed the Dermatology Life Quality Index (DLQI) [15].

\section{Statistical analysis}

All data were assessed for normal or non-normal distribution to apply parametric or nonparametric statistical tests. Differences between groups were determined using the Mann-Whitney U-test and Kruskal-Wallis test. Correlations were determined by Spearman correlation analysis. A multivariate regression analysis was performed to prove whether the variables significantly influencing the stigmatization level are indeed independent. The level of significance was set to $\alpha=0.05$. The resulting $p$-values were considered significant if $p<0.05$. Statistical analyses were performed using Statistica 12 software (StatSoft, Tulsa, USA).

\section{Results}

The vast majority of studied patients showed feelings of stigmatization due to psoriasis. According to the 6-item Stigmatization Scale the mean level of stigmatization was $5.6 \pm 4.5$ points. Only $13(12.0 \%)$ patients had no feelings of stigmatization (0 points) and a further 18 (16.7\%) patients were minimally stigmatized (1-2 points). The most troublesome aspect for psoriatic suffers was the problem of psoriasis being considered by others as a contagious disease and that people are staring at psoriasis lesions (Table 2 ).

The mean level of stigmatizations assessed by the Feelings of Stigmatization Questionnaire was $98.4 \pm 26.4$ points. Positive attitudes and feeling of being flawed were the most important aspects of stigmatization expressed by patients (Table 3 ).

Both stigmatization questionnaires correlated with each other $(p<0.0001 ; r=-0.53)$.

Involvement of the face played an important role in the stigmatization level of psoriatic patients $(p<0.0001$ and $p=0.003$ for 6 -item Stigmatization Scale and Feelings of Stigmatization Questionnaire, respectively) (Figures $1 \mathrm{~A}, \mathrm{~B})$. Severity of psoriasis significantly correlated with the stigmatization level $(r=0.27 ; p=0.005$ and $r=$ -0.24; $p=0.01$ for 6-item Stigmatization Scale and Feelings of Stigmatization Questionnaire, respectively), but a multivariate analysis revealed that only face involvement, not PASI, was an independent factor responsible for the level of stigmatization. Itching was also a potential factor influencing feelings of stigmatization. Patients with itching were more stigmatized compared to those free from this symptom $(p=0.08$ and $p=0.02$ for 6 -item Stigmatization Scale and Feelings of Stigmatization Questionnaire, respectively). Moreover, intensity of itching significantly correlated with stigmatization level according to the 6-item Stigmatization Scale $(r=0.14$, $p=0.04)$. However, no such relationship was revealed for the Feelings of Stigmatization Questionnaire $(r=-0.15$, $p=0.11$.

Gender, age, marital status, education level, employment, place of living as well as family history of psoriasis did not play an important role in the feelings of stigmatization of studied psoriatic patients (data not shown). Stigmatization level assessed by both instruments significantly correlated with the impairment of quality of life (DLQI) $(r=0.56, p<0.0001$ and $r=-0.48, p<0.0001$ for

Table 2. Feelings of stigmatization according to 6-item Stigmatization Scale [13]

\begin{tabular}{|c|c|c|c|c|c|}
\hline Question & $\begin{array}{l}\text { Not at all } \\
n(\%)\end{array}$ & $\begin{array}{l}\text { Sometimes } \\
n(\%)\end{array}$ & $\begin{array}{l}\text { Very often } \\
n(\%)\end{array}$ & $\begin{array}{l}\text { Always } \\
n(\%)\end{array}$ & Mean \pm SD \\
\hline 1. Others are not attracted to me due to my skin disease & 48 & 33 & 18 & 9 & $0.89 \pm 0.97$ \\
\hline 2. I think that others stare at my skin disease & 31 & 39 & 21 & 17 & $1.22 \pm 1.03$ \\
\hline 3. Others feel uncomfortable touching me due to my skin disease & 46 & 31 & 20 & 11 & $0.96 \pm 1.01$ \\
\hline 4. Other people think that my skin disease is contagious & 27 & 43 & 16 & 21 & $1.31 \pm 1.06$ \\
\hline 5. Other people avoid me due to my skin disease & 72 & 22 & 10 & 4 & $0.50 \pm 0.82$ \\
\hline $\begin{array}{l}\text { 6. Other people sometimes make annoying comments about } \\
\text { my skin disease }\end{array}$ & 54 & 38 & 11 & 5 & $0.69 \pm 0.84$ \\
\hline
\end{tabular}


Table 3. Feelings of stigmatization according to Feelings of Stigmatization Questionnaire [14]

\begin{tabular}{lccccc}
\hline Variable & Items, $n$ & Mean \pm SD & $\begin{array}{c}\text { Scoring per question } \\
\text { Mean } \pm \text { SD }\end{array}$ & Minimum & Maximum \\
\hline Feelings of stigmatization (total) & 33 & $98.39 \pm 26.4$ & $2.98 \pm 0.8$ & 16 & 145 \\
\hline Anticipation of rejection & 8 & $22.28 \pm 8.8$ & $2.79 \pm 1.1$ & 0 & 37 \\
\hline Feeling of being flawed & 6 & $20.83 \pm 7.0$ & $3.47 \pm 1.2$ & 0 & 30 \\
\hline Sensitivity to the opinions of others & 5 & $15.31 \pm 5.4$ & $3.06 \pm 1.1$ & 0 & 25 \\
\hline Guilt and shame & 5 & $13.44 \pm 4.2$ & $2.69 \pm 0.8$ & 1 & 25 \\
\hline Secretiveness & 5 & $9.32 \pm 3.7$ & $1.86 \pm 0.7$ & 0 & 19 \\
\hline Positive attitudes & 4 & $17.15 \pm 4.7$ & $4.29 \pm 1.2$ & 4 & 25 \\
\hline
\end{tabular}
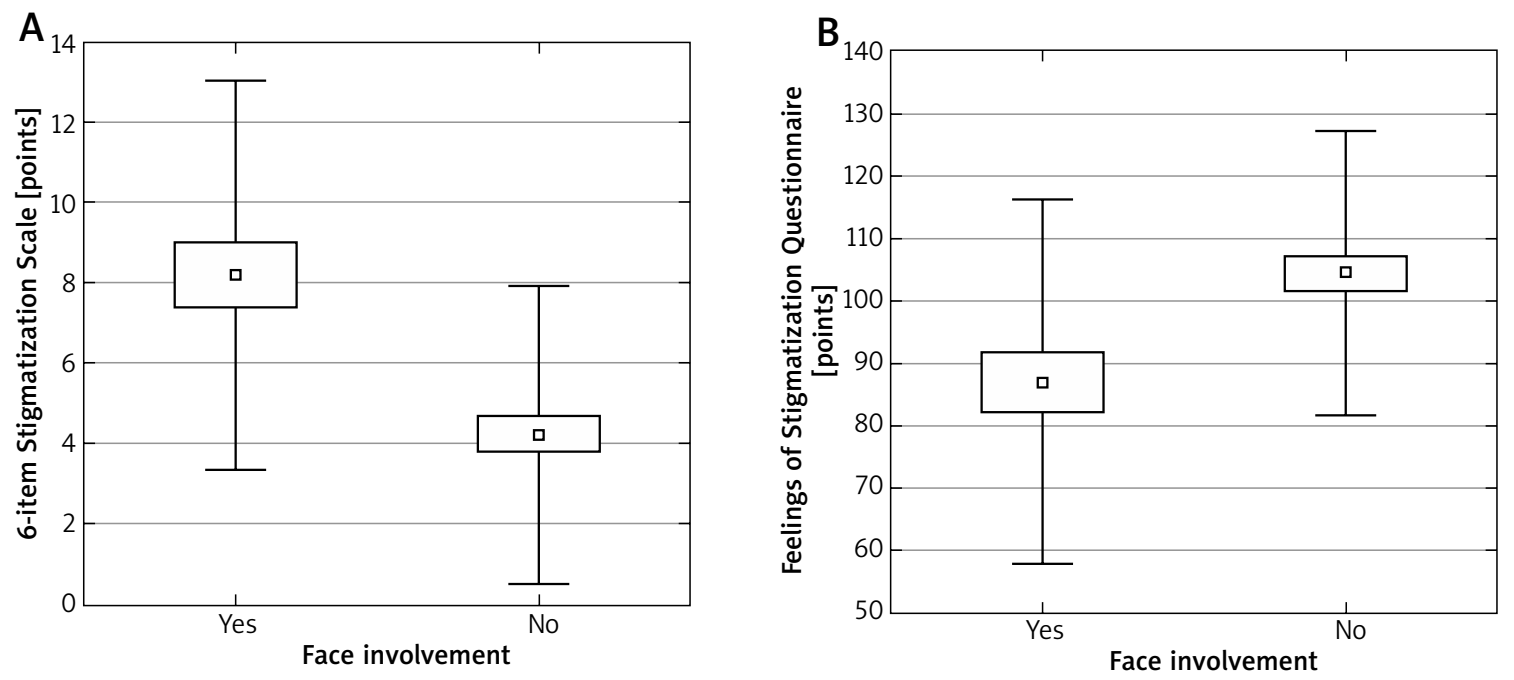

$\square$ Mean $\square$ Mean \pm standard error IMean \pm standard deviation

Figure 1. Face involvement and stigmatization (A - 6-item Stigmatization Scale, B - Feelings of Stigmatization Questionnaire) in psoriatic patients

A

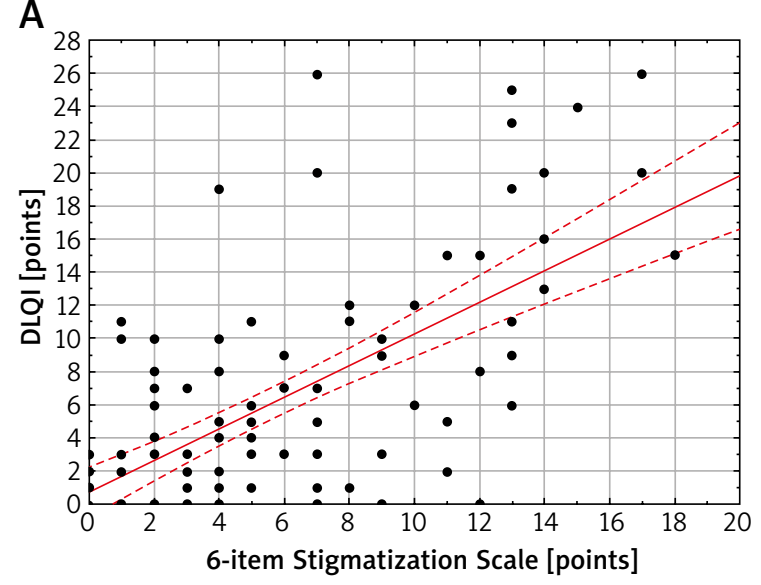

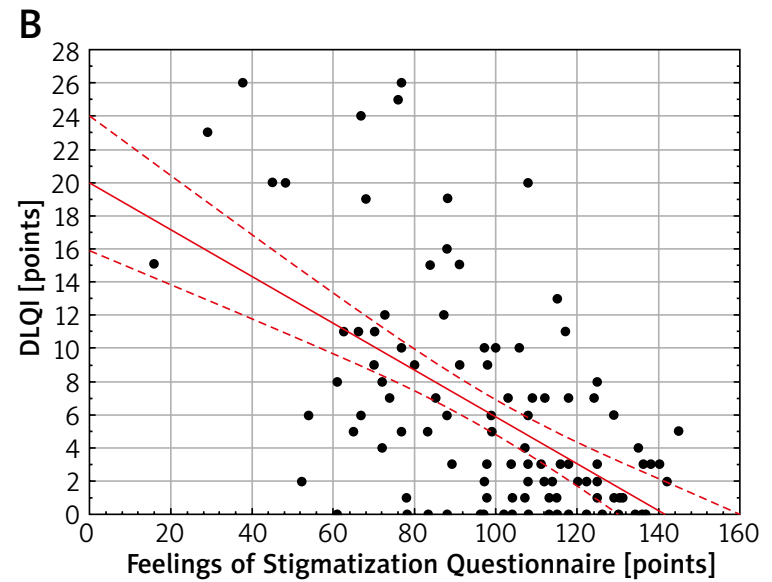

Figure 2. Correlation between quality of life (Dermatology Life Quality Index - DLQI) and stigmatization level (A - 6-item Stigmatization Scale; B - Feelings of Stigmatization Questionnaire) 
6-item Stigmatization Scale and Feelings of Stigmatization Questionnaire, respectively) (Figures 2 A, B).

\section{Discussion}

Despite the fact that stigmatization experience in psoriatic patients is well recognized, there is no worldwide accepted program or guideline for its measurement or to properly address it. Recently, more often statements in favor of a holistic approach to people suffering from psoriasis have been heard, but no widely accepted activity in daily practice to recognize and address the stigmatization exists. We believe there is still not enough attention from the medical community regarding stigmatization in general in dermatology and particularly among psoriatic patients. Moreover, properly addressing the problem has to consider national, regional, cultural, ethnic, etc. specificity. Therefore, studies on stigmatization in different populations are needed.

To the best of our knowledge the current study is the first one on stigmatization in Arabic patients suffering from cutaneous disorders. It is clear that having a proper instrument for recognition and measurement of stigmatization experience is the first important step in the process of properly addressing the problem, as well as planning and applying anti-stigma activity. Our research used skin-related stigmatization questionnaires in Arabic language versions previously prepared by our group [12]. We believe that availability of these instruments will allow more data on stigmatization in Arabic dermatologic patients to be obtained in the future.

Our research found that the mean level of stigmatization in Arabic psoriatic patients was $5.6 \pm 4.5$ points. A similar result was obtained from another study among a Polish population of psoriatic patients, where the mean level of stigmatization was $5.0 \pm 3.7$ points [16]. The percentage of psoriatic patients without feelings of stigmatization and minimally stigmatized was $12 \%$ and $16.7 \%$ in our study and $9.8 \%$ and $18.3 \%$ in the Polish study, respectively. Both studies found that the most troublesome aspect of psoriasis for studied subjects was the problem of other people staring at skin lesions and the fact that other persons consider psoriasis to be a contagious disease [16]. According to the Feelings of Stigmatization Questionnaire, positive attitudes and the feeling of being flawed were the most important aspects of stigmatization in the Arabic population of psoriatic subjects. Hrehorow et al. [16] documented that Polish patients underlined the importance of anticipation of rejection and, similarly to Arabic patients, the feeling of being flawed. This discrepancy may be explained by marked cultural differences between the two populations. Two studies performed in the Netherlands, analyzing 514 [17] and 131 [13] psoriatic individuals, found feelings of stigmatization present in $73-79 \%$ of patients. Another study ascertained that 1 in 5 patients with psoriasis experienced strong re- jection, usually in the following situations: going to the gym, going to the swimming pool, going to the hairdressers, or at a job place [18]. Development of psoriasis at a younger age was suggested to be a predisposing factor to experiencing a feeling of stigmatization [19]. Both Hrehorow et al. [16] and Vardy et al. [20] showed that stigmatization level correlated with impairment of quality of life. This was also confirmed in the current study.

We are aware of some limitations of our study. Our research was performed only in a single center. At the same time, one has to mention that it is the biggest dermatology department with inpatients from all around the country. Most of the patients who participated in the study were already under treatment. In fact, all patients on systemic treatment, except one (on acitretin), were on various biological agents. This is a local phenomenon. It is important to note that access to biological treatment is quite easy in the UAE in comparison to most European countries. In fact, there is no problem with the initiation of biological treatment from the first visit of a patient who requires systemic treatment (all registered biologics: etanercept, adalimumab, infliximab, ustekinumab, secukinumab and ixekizumab are available). For that reason, most of our consecutive psoriasis patients had mild disease. However, despite the above-described situation we were able to show that the majority of psoriatic subjects experienced a feeling of stigmatization.

\section{Conclusions}

This study is the first available attempt to assess stigmatization experience among psoriatic patients in an Arabic country. We believe it will bring more attention to this problem among the medical community and will be considered in the program of a holistic approach to psoriatic individuals. Certainly there is a need for more research in the field of skin-related stigmatization in Arabic countries.

\section{Conflict of interest}

The authors declare no conflict of interest.

\section{References}

1. Jankowiak B, Kowalewska B, Fiodaravich Khvorik D, et al. The level of stigmatization and depression of patients with psoriasis. Iran J Public Health 2016; 45: 690-2.

2. Richards HL, Fortune DG, Main CJ, Griffiths CE. Stigmatization and psoriasis. Br J Dermatol 2003; 149: 209-11.

3. Richards HL, Fortune DG, Griffiths CE, Main CJ. The contribution of perceptions of stigmatization to disability in patients with psoriasis. J Psychosom Res 2001; 50: 11-5.

4. Falk G. Stigma: How We Treat Outsiders. NY, Prometheus Books, New York 2001.

5. Halioua B, Cribier B, Frey M, Tan J. Feelings of stigmatization in patients with rosacea. J Eur Acad Dermatol Venereol 2017; 31: 163-8. 
6. Dimitrov D, Szepietowski JC. Stigmatization in dermatology with a special focus on psoriatic patients. Postep Hig Med Dosw 2017; 71: 1015-22.

7. Griffiths CEM, Barker JNWN. Psoriasis. In: Rook's Textbook of Dermatology. $8^{\text {th }}$ edn. Burns DA, Breathnach SM, Cox NH, Griffiths CEM (eds). Blackwell Publishing Ltd. 2010; 20.120.60.

8. Gupta M, Gupta A. Depression and suicide ideation in dermatology patients with acne, alopecia areata, atopic dermatitis and psoriasis. Br J Dermatol 1998; 139: 846-50.

9. Schmid-Ott G, Jaeger B, Kuensebeck HW, et al. Dimensions of stigmatization in patients with psoriasis in a "Questionnaire on Experience with Skin Complaints". Dermatology 1996; 193: 304-10.

10. Fredriksson T, Pettersson U. Severe psoriasis: oral therapy with a new retinoid. Dermatologica 1978; 157: 238-44.

11. Reich A, Heisig M, Phan NQ, et al. Visual analogue scale: evaluation of the instrument for the assessment of pruritus. Acta Derm Venereol 2012; 92: 497-501.

12. Dimitrov D, Matusiak $九$, Evers AWM, et al. Arabic language skin-related stigmatization instruments: translation and validation process. Adv Clin Exp Med 2019; 28: doi:10.17219/ acem/102617.

13. Lu Y, Duller P, van der Valk PGM, Evers AWM. Helplessness as predictor of perceived stigmatization in patients with psoriasis and atopic dermatitis. Dermatol Psychosom 2003; 4: 146-50.

14. Ginsburg IH, Link BG. Feelings of stigmatization in patients with psoriasis. J Am Acad Dermatol 1989; 20: 53-63.

15. Finlay AY, Khan GK. Dermatology Life Quality Index (DLQI): a simple practical measure for routine clinical use. Clin Exp Dermatol 1994; 19: 210-6.

16. Hrehorow E, Salomon J, Matusiak L, et al. Patients with psoriasis feel stigmatized. Acta Derm Venereol 2012; 92: 67-72.

17. van Beugen S, van Middendorp H, Ferwerda M. Predictors of perceived stigmatization in patients with psoriasis. $\mathrm{Br}$ J Dermatol 2017; 176: 687-94.

18. Ginsburg IH, Link BG. Psychosocial consequences of rejection and stigma feelings in psoriasis patients. Int I Dermato 1993; 32: 587-91.

19. Perrott SB, Murray AH, Lowe J, Mathieson CM. The psychosocial impact of psoriasis: physical severity, quality of life, and stigmatization. Physiol Behav 2000; 70: 567-71.

20. Vardy D, Besser A, Amir M, et al. Experiences of stigmatization play a role in mediating the impact of disease severity on quality of life in psoriasis patients. Br I Dermatol 2002; 147: 736-42. 